\title{
Does the osteon morphology depend on the body mass? A scaling study on macroscopic and histomorphometric differences between cow (Bos taurus) and sheep (Ovis aries)
}

\author{
Marco Zedda' ${ }^{1}$ D $\cdot$ Ramona Babosova ${ }^{2}$ D
}

Received: 3 August 2020 / Revised: 7 January 2021 / Accepted: 12 January 2021 / Published online: 10 February 2021

(c) The Author(s) 2021

\begin{abstract}
The structure and geometry of bone depend on many biological and environmental factors. These factors affect the bone tissue's microstructure differently, and their interaction has not yet been fully elucidated. Our research investigated the effect of body mass on the macro- and microstructure of the compact bone. Therefore we analyzed the humerus and femur bones from females of 11 cows and 11 sheep at the age of 4-10 years. Both species have very similar dietary and locomotion patterns, but their body size and weight are very different. Within macroscopical analyzes of bones were observed ascending order of robustness index and bone diaphysis index. In both animals, plexiform and irregular Haversian bone tissues were identified in humerus and femur. Conversely, the dense Haversian tissue present only in cow above all in the femur. The most considerable interspecific osteonal difference between sheep and cow was in the osteon density, whose average value is $37 \%$ higher in the cow. The osteons of sheep humerus are almost circular, and osteons of cow femur are more elliptical. Within both species, the femoral osteons are elliptical than those of humerus. Despite the cow weighing more than 10 times the sheep, the measurements of osteons and Haversian canals, are very similar (the values of the ratio cow/sheep for these types are comprised from 1.04 to 1.86). Our findings indicate that the body mass does not affect the size of bone microstructure, probably more sensitive to other factors as a lifestyle and locomotor ability.
\end{abstract}

Keywords Cow $\cdot$ Sheep $\cdot$ Humerus $\cdot$ Femur $\cdot$ Histomorphometry $\cdot$ Allometry

\section{Introduction}

Mammalian bones are characterized by high variability in the organization of bone microstructure and the degree of vascularization (geometry of secondary osteons and Haversian canals). These specific species differences depend on several factors, such as the systematic classification of the individual (species, breed), or biological and environmental factors (Brits et al. 2014; Zedda et al. 2015). Several studies

Marco Zedda

mzedda@uniss.it

Ramona Babosova

rbabosova@ukf.sk

1 Department of Veterinary Medicine, University of Sassari, via Vienna 2, 07100 Sassari, Italy

2 Department of Zoology and Anthropology, Constantine the Philosopher University in Nitra, Nabrezie mladeze 91, 94974 Nitra, Slovakia describe various causes that can, to some extent, affect the microstructure of bone tissue and cause not only interspecies but also intraspecific differences. Such causes include, for example, age, sex, body size and weight, bone size, the pressure exerted on the bone during life, movement, lifestyle, pathological conditions, or heredity (Britz et al. 2009; Felder et al. 2017).

The individual factors affect the microstructure of the bone tissue differently, and their interaction has not yet been fully elucidated (Britz et al. 2009). Already Martin et al. (1980) described in their research that the size of secondary osteons decreases with increasing age, causing declining osteoclast activity. However, according to Urbanova and Novotny (2005), no significant differences were observed between either sex within the microstructure of bone tissue of several animal taxa.

The research of Felder et al. (2017) suggests that the minimum diameter of secondary osteons is only minimally affected by the animal's body weight and is rather related to the size of the erythrocytes. On the contrary, the authors 
noted a strong influence of adults' body weight on the maximum values of the area of secondary osteons. This statement is also confirmed by the research of Lozupone and Favia (1990). Authors assumed that the maximum values of the area of secondary osteons and Haversian canals might differ between animals due to their different weights. Joshi (2006) found that with increasing body weight, the values of secondary osteons and Haversian canals also increase. The influence of weight on the bone microstructure was also discussed by Jowsey (1966), who, based on a comparison of several animal species, concluded that the size of secondary osteons increased with increasing animal weight, and the size of secondary osteons remained stable from about $10 \mathrm{~kg}$. Gibson et al. (2006) assume that the maximum values of secondary osteons are related to nutrient transport. On the other hand, Britz et al. (2009) suppose that the effect of an individual's weight on the size of secondary osteons is associated with the pressure on the bone induced by mechanical stress. Van Oers et al. (2008) state that with increasing tension and pressure exerted on the bone, the size of secondary osteons decreases indirectly.

Bone size is an important factor in the analysis of bone microstructure. In mammals, remodeling correlates with bone size rather than anything else. Robust bones (i.e., broad in length) tend to have larger and more numerous osteons than thinner bones (Goldman et al. 2014). According to Nguyen et al. (2003), genetic factors are responsible for 60 to $80 \%$ of bone size variance. Similarly, the study by Ruffing et al. (2006) suggests that bone size is determined by a complex combination of genetic, vital, and nutritional factors. Skedros et al. (2003, 2013) observed that changes in bone shape, area, and cross-sectional density correlated with biomechanical loading. In particular, with an increasing body weight of various animal species, long bones become stronger and more resilient than would be expected (Schmidt-Nielsen 1984). This disproportionate increase in bone size was described by Galileo Galilei (1564-1642) for the first time in his Discorsi e dimostrazioni matematiche intorno a due nuove scienze (1638). Some studies (Bell et al. 2001; Burr 2002; Martin 2003) suggest that larger osteons are sensitive to microfracture and, therefore, undergo targeted remodeling.

Several studies report that the structure and geometry of secondary osteons and Haversian canals depend on biological and environmental factors (Gentry 1970; Hillier and Bell 2007). Owerkowicz and Crompton (1995) noted more secondary osteons in free-range animals, suggesting a correlation between different bone types and biomechanical stress. In particular, the presence, distribution and size of secondary osteons were justified by biomechanical stresses of different intensity (Zedda et al. 2008; Ascenzi and Roe 2012; Caeiro et al. 2013). Higher osteonal density was observed in wild boars than domestic pigs (Alioniene 2004; Mainland et al.
2007; Zedda et al. 2019), in moufflons and goats than in sheep (Giua et al. 2014; Zedda et al. 2017). The decrease in osteon density is mainly due to domestication, and limited physical activity (locomotory activity) described comparing prehistoric horses and cows to contemporary individuals (Dittmann 2003).

The size of osteons and Haversian canals is related to the amount of biomechanical stress affecting bones, while it is possible to take information on locomotor behavior, not only in extant but also in extinct mammals (Pfeiffer et al. 2006; Nacarino-Meneses et al. 2016; Zedda et al. 2020). Higher Haversian canals occur in animals with greater mobility, associated with the need to improve blood supply (Owerkowicz and Crompton 1995). Consequently, the study of bone tissue could also be a useful tool to reconstruct the mammals' locomotion behavior.

Our research was focused on the observation of macroscopic and microscopic differences between the humerus and femur of cows and sheep. Both animals are very similar in dietary and locomotion pattern, but their body size and weight are very different. We investigated whether the presumed macroscopic differences are related to differences in bone microstructure at the interspecies and intraspecific levels. Our results may contribute to a better understanding of how body size affects bone microstructure and biomechanical properties. Therefore, a histomorphometric study of a small bone fragment could be of interest to archaeozoologists, forensic anthropologists, and palaeontologists to reconstruct important information about the body size of the individual to whom it belonged.

\section{Material and methods}

\section{Sampling and bone preparation}

Our research was conducted on the humerus and femur bones from 11 cows (Bos taurus) and 11 sheep (Ovis aries). The number of 11 individuals ensured a heterogeneous sampling for each species to compare them. In contrast, the evaluation of the inter-individual differences within each species was not the aim of our work. All bones belong to the osteological collection of the Department of Veterinary Medicine of the University of Sassari (Italy), where thousands of bones from domestic and wild animals are available for reference. Animals were adults and regularly butchered in local slaughterhouses following a medical examination that has ascertained their good health. Cows and sheep were of local breeds typical of Sardinia, where the farming system, for both species, is grazing in the wild. Animals spent much of their time walking to collect grass. They knew no shelters and lived almost outdoor all day and in all seasons. No evidence of skeletal pathology in both 
species was detected. The age range, determined according to the skeleton ossification (Barone 1980), was estimated in analysed animals at $4-10$ years. For this research, only bones belonging to female individuals were chosen to avoid possible morphometric differences due to sexual dimorphism. After removing soft tissues with periosteal elevators and knives, the bones were macerated in cold water for 2 weeks, and water changes every 3 days. Then they were dried in a stove (Fig. 1).

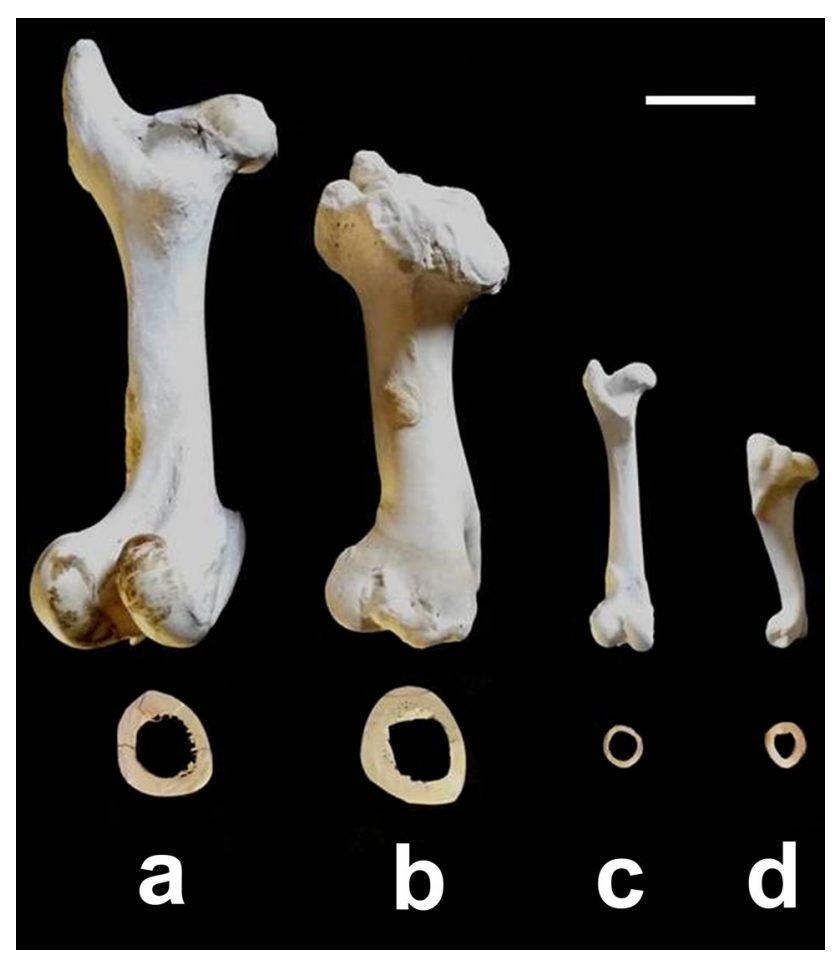

Fig. 1 Long bones studied: from left to right: $\mathbf{a}$ femur of cow; $\mathbf{b}$ humerus of cow; $\mathbf{c}$ femur of sheep; $\mathbf{d}$ humerus of sheep. Whole left bones in caudal view (up) and corresponding bone rings at the level of diaphysis (below). $\mathrm{Bar}=8 \mathrm{~cm}$

\section{Osteometry}

To detect measurements of bone sizes, the bones underwent osteometrical analyses using a digital calliper. The greatest length (GL), the maximum (maxDD), and minimum diaphyseal diameters (minDD) have been taken before the crosssectioning of the bones. On their bases, the bone robusticity index (RI), as [(maxDD + minDD)/GL per 100], has been calculated (Stock and Shaw 2007).

An angular grinder (Telefunken) with a $0.8 \mathrm{~mm}$ thick inox disk (Dexter) was used to obtain $2 \mathrm{~mm}$ thick cross-sectional rings from the smallest width of their diaphyses (midshaft) (Fig. 1). The bone sections were cleaned for 2 days in an aqueous solution with a laundry detergent containing proteolytic enzymes, at temperature $37^{\circ} \mathrm{C}$. After bone crosssectioning, diaphysis rings were scanned. From digitalized images, the following measurements were taken. Values were calculated using the software Scion Image (Scion Corporation, Frederick, MD, USA): D1-area of the bone diaphysis (including the medullary cavity); D2-area of the medullary cavity; D3-area of the bone tissue in the diaphysis (that corresponds to D1-D2); BDI-bone diaphysis index corresponding to percentage ratio between bone tissue in the diaphysis and area of the bone diaphysis $(\mathrm{D} 3 / \mathrm{D} 1 \times 100)$. These parameters are listed in Table 1.

The air-dried bony rings were ground and thinned using a fine sandpapering machine. Samples were sanded by hand with emery paper to obtain about $50 \mu \mathrm{m}$ thick sections. After thorough washing to remove debris, the cross-sections were fixed onto glass slides with Eukitt (Merck, Darmstadt, Germany).

\section{Microscopy and histomorphometry}

Sections of all bones were observed and photographed using a Zeiss Axiophot microscope at $2.5 \times, 10 \times$, and $20 \times$ magnifications. The qualitative histological characteristics of the
Table 1 Osteometrical data of humerus and femur of sheep and cow (mean \pm standard deviation)

\begin{tabular}{|c|c|c|c|c|c|c|}
\hline & \multicolumn{3}{|c|}{ Sheep (Ovis aries) } & \multicolumn{3}{|c|}{ Cow (Bos taurus) } \\
\hline & Humerus & Femur & $h / f \%$ & Humerus & Femur & $h / f \%$ \\
\hline W & $106.2 \pm 21$ & $81.7 \pm 15$ & 133.8 & $910.9 \pm 92$ & $1,107.2 \pm 106$ & 82.3 \\
\hline GL & $170 \pm 11$ & $205 \pm 14$ & 82.9 & $312 \pm 17$ & $395 \pm 21$ & 78.9 \\
\hline Min DD & $21 \pm 2$ & $23 \pm 3$ & 91.3 & $54 \pm 4$ & $49 \pm 7$ & 110.2 \\
\hline Max DD & $26 \pm 3$ & $25 \pm 4$ & 104.0 & $60 \pm 6$ & $54 \pm 8$ & 111.1 \\
\hline D1 & $418.6 \pm 33$ & $417.1 \pm 28$ & 100.4 & $2,539.6 \pm 184$ & $2,014.5 \pm 152$ & 126.1 \\
\hline D2 & $115.2 \pm 7$ & $188.7 \pm 13$ & 61.1 & $683.2 \pm 62$ & $719.9 \pm 54$ & 94.9 \\
\hline D3 & $303.4 \pm 29$ & $228.4 \pm 11$ & 132.8 & $1,856.4 \pm 185$ & $1,294.6 \pm 96$ & 143.4 \\
\hline RI & 27.6 & 23.4 & 117.9 & 36.5 & 26.1 & 139.8 \\
\hline BDI & 72.5 & 54.8 & 132.3 & 73.1 & 64.3 & 113.7 \\
\hline
\end{tabular}

Values of $\mathrm{W}$ are expressed in gr, those of GL, minDD and maxDD in $\mathrm{mm}$, those of D1, D2 and D3 in $\mathrm{mm}^{2}$ and RI, BDI are indexes (see text) 
compact bone were determined according to the classification of Francillon-Vieillot (1989) and reported in Table 2. In all sections, 486 secondary osteons were examined (127 in sheep humeri, 120 in sheep femora, 125 in cow humeri and 114 in cow femora). Only the secondary osteons where the cement line was well-evident have been taken into account, and the bone lamellae were counted based on the position of osteocyte lacunae. The quantitative (histomorphometrical) variables were assessed using the software Scion Image. We measured the area, perimeter, minimum, and maximum diameters of Haversian canals and secondary osteons to minimize differences in bone locations. All these parameters have been indicated according to the report (Parfitt et al. 1987) of the Histomorphometry Nomenclature Committee of the ASBMR (American Society for Bone and Mineral

Table 2 Morphological observations on the histological differences in bone tissue type composition between humerus and femur of sheep (Ovis aries) and cow (Bos taurus)

\begin{tabular}{llllll}
\hline Bone tissue types & \multicolumn{2}{l}{ Ovis aries } & & \multicolumn{2}{l}{ Bos taurus } \\
\cline { 2 - 3 } \cline { 5 - 6 } \cline { 5 - 6 } & Humerus & Femur & & Humerus & Femur \\
\hline Plexiform & +++ & ++ & + & + \\
Irregular Haversian & ++ & +++ & +++ & ++ \\
Dense Haversian & - & - & ++ & +++ \\
\hline
\end{tabular}

+ indicates the bone tissue present in traces; ++ the tissue with intermediate presence; +++ the bone tissue most present; - the bone type absent
Research) and listed in Table 3. The area of secondary osteon included the Haversian canal. Only measurements from intact secondary osteons were taken for statistical analysis. The eccentricity of Haversian canals and secondary osteons were also evaluated and calculated considering that eccentricity $(e)=$ square root of $1-(b / a)^{2}$, where a is the semi-major axis, and $b$ is the semi-minor axis. Osteon density, which describes the number of secondary osteons per square mm was also assessed and compared between two bone types and two species. The entire sections were scanned with a digital scanner (Motic Easy Scan One, Motic, Hong Kong) using a PlanApochromat $10 \times / 0.3$ objective to measure the osteon density. All bone specimens and slides are deposited at the Department of Veterinary Medicine of the University of Sassari.

\section{Statistical analysis}

Measurements were repeated to evaluate intra- and interobserver variability. Statistical analyses were done using the NCSS software program. Mean and standard deviation were calculated for each parameter. The Pearson's correlation coefficient between the size of osteons and Haversian canals for each bone type and each species has been calculated, and the linear regression has been drawn in the regression plotter. Correlation coefficients were considered on the basis of the classification proposed by Hinkle et al. (2003) as follows: very high positive correlation (0.90-1.00), high positive correlation $(0.70-0.90)$, moderate positive correlation

Table 3 Comparison of histomorphometrical data between humerus and femur of sheep (Ovis aries) and cow (Bos taurus)

\begin{tabular}{|c|c|c|c|c|c|}
\hline & \multirow{2}{*}{$\begin{array}{l}\text { Histomorphomet- } \\
\text { ric terms }\end{array}$} & \multicolumn{2}{|l|}{ Ovis aries } & \multicolumn{2}{|l|}{ Bos taurus } \\
\hline & & Humerus & Femur & Humerus & Femur \\
\hline Osteon population density & On.Dn & $2.6 \pm 0.5$ & $2.8 \pm 0.9$ & $3.5 \pm 1.2$ & $3.9 \pm 1.1$ \\
\hline Number of measured osteons & - & 127 & 120 & 125 & 114 \\
\hline Number of lamellae & - & $4-5$ & $5-6$ & $6-7$ & $7-8$ \\
\hline \multicolumn{6}{|l|}{ Osteons } \\
\hline Maximum diameter & $\operatorname{maxOn.Dm}$ & $134.2 \pm 74$ & $161.3 \pm 51$ & $151.6 \pm 37$ & $194.1 \pm 29$ \\
\hline Minimum diameter & $\operatorname{minOn} . \mathrm{Dm}$ & $120.7 \pm 36$ & $128.4 \pm 45$ & $117.9 \pm 83$ & $121.3 \pm 14$ \\
\hline Mean diameter & On.Dm & 126.2 & 146.9 & 134.4 & 158.5 \\
\hline Perimeter & On.Pm & $404.3 \pm 71$ & $482.5 \pm 39$ & $425.7 \pm 54$ & $512.1 \pm 94$ \\
\hline Area & On.Ar & $12,753.0 \pm 1304$ & $17,541.4 \pm 1647$ & $13,675.6 \pm 1623$ & $19,852 \pm 2306$ \\
\hline Eccentricity & - & 0.43 & 0.64 & 0.65 & 0.78 \\
\hline \multicolumn{6}{|l|}{ Haversian canals } \\
\hline Maximum diameter & $\operatorname{maxHC.Dm}$ & $28.4 \pm 7$ & $26.2 \pm 4$ & $40.8 \pm 7$ & $37.7 \pm 8$ \\
\hline Minimum diameter & $\operatorname{minHC} . \mathrm{Dm}$ & $24.1 \pm 5$ & $22.8 \pm 8$ & $26.9 \pm 12$ & $23.2 \pm 10$ \\
\hline Mean diameter & HC.Dm & 26.0 & 24.5 & 33.4 & 29.7 \\
\hline Perimeter & HC.Pm & $82.3 \pm 54$ & $75.2 \pm 9$ & $112.9 \pm 33$ & $114.2 \pm 40.7$ \\
\hline Area & HC.Ar & $421.3 \pm 51$ & $413.5 \pm 63$ & $794.7 \pm 127.0$ & $725.8 \pm 116.9$ \\
\hline Eccentricity & - & 0.51 & 0.59 & 0.73 & 0.82 \\
\hline
\end{tabular}

Values of diameters, perimeter, and area are expressed in $\mu \mathrm{m}\left(\right.$ area in $\left.\mu \mathrm{m}^{2}\right) \pm$ standard deviation 
(0.50-0.70), low positive correlation (0.30-0.50), little if any correlation $(0.30$ to -0.30$)$, low negative correlation $(-0.30$ to -0.50$)$, moderate negative correlation $(-0.50$ to -0.70$)$, high negative correlation $(-0.70$ to -0.90$)$ and very high negative correlation $(-0.90$ to -1.00$)$. Variances within the size of osteons and Haversian canals, in humerus and femur and between sheep and cow, were analyzed for statistical significance $(p<0.05)$ using one-way ANOVA with Bonferroni post-hoc test.

\section{Withers height and body mass}

To estimate the withers height starting from the measurement of the humerus and femur formulations reported in the literature have been taken into account for cow (Matolcsi 1970) and sheep (Teichert 1975; May and Teichert 2001). Based on these data, the withers height of cow was calculated in $125-135 \mathrm{~cm}$ and sheep about $65 \mathrm{~cm}$. The body mass was estimated at $450 \mathrm{~kg}$ for cow and $43 \mathrm{~kg}$ for sheep based on the mean data provided by the local slaughterhouses where the bones came from and following the reasoning discussed by Scott (1990) and Mysterud et al. (2001).

\section{Results}

The macroscopical data coming from measurements of whole and sectioned bones are reported in Table 1, where the robustness index (RI) and the bone diaphysis index (BDI) are also shown. The difference size between humerus and femur within each species was observed. It can be noted that the femur is always longer, as the greatest length of the humerus is $82.9 \%$ (in sheep) and $78.9 \%$ (in cow) of the corresponding value of femur. However, almost all the diaphysis diameters are bigger in the humerus than the femur, except for the minimum diameter (minDD) in sheep. That means that the humerus is stockier and more robust than the femur. The robustness index (RI) of the humerus is higher than the femur in both species $(+17.9 \%$ in sheep and $+39.8 \%$ in cow). The values of the area occupied by bone tissue in diaphysis sections (D3) confirm these data, as they are always wider in the humerus $(+32.8 \%$ in sheep and $+43.4 \%$ in cow). Interesting to note that the list of bones ordered in ascending order of robustness index RI (sheep femur, cow femur, sheep humerus, and cow humerus) is the same as that of bones ordered in ascending order of bone diaphysis index BDI. It suggests a strict correlation between the robustness appreciable from the outside and the extension of the bone tissue forming the diaphysis. Worth to note that within each species, the humerus and femur are different in weight. Indeed, in sheep, the humerus is heavier than femur $(+33.8 \%)$, whereas, in cow, the humerus is lighter than femur $(-17.7 \%)$.
Regarding the histomorphological features of the bones studied, the tissues recognized are three: plexiform, irregular Haversian, and dense Haversian. Their presence and amount differ between humerus and femur in each species, and they are summarized in Table 2. The plexiform tissue, also named the fibrolamellar system, consists of a net of primary vascular canals well-ordered into a regular plexus (Figs. 2a and c; 3a). Irregular Haversian tissue contains solitary and separated secondary osteons (Figs. 2b and d; 3b). Dense Haversian tissue is characterized by numerous secondary osteons arranged close to each other to form often large groups (Fig. 3c, and d). The secondary osteons of both irregular and dense Haversian tissues are made by a central Haversian canal, having mainly a direction parallel to the length of the diaphysis, surrounding by a variable number of bone lamellae (Fig. 4). The plexiform tissue is present in all the bones examined, even if its higher amount is detectable in bones of sheep, mainly in the humerus. The irregular Haversian tissue is also present in all bones of each species, with no vast differences in amount. Conversely, the dense Haversian tissue appears absent in sheep and present only in cow above all in the femur. As schematically shown in Table 2, in sheep. The bone type most widespread is the plexiform tissue in the humerus and irregular Haversian tissue in the femur. While in cow, the descending order of extension is irregular Haversian, dense Haversian and plexiform tissue in the humerus and dense Haversian, irregular Haversian, and plexiform in the femur.

A different morphological feature is detectable in osteons of sheep and cow. As reported in Table 3, the number of bone lamellae surrounding the Haversian canal and forming the osteon is mainly 4-6 in sheep and 6-8 in the cow (Fig. 4), with few differences between humerus and femur. In both species, the femur's osteons are made on average of one or two more bone lamellae than the humerus. This datum agrees with the morphometrical values taken from the osteon size and reported in Table 3, where the mean diameter of osteons $(\mathrm{On} . \mathrm{Dm})$ is bigger in bones of the cow than the corresponding bones of the sheep. However, this difference is minimal, around $+8 \%$ for the femur and $+6 \%$ for the humerus. Within each species, the largest size of the osteon's mean diameter in femur when compared to the humerus is about $+16 \%$ in sheep and $+18 \%$ in the cow. The greatest interspecific osteonal difference between sheep and cow is in the osteon density (On.Dn) whose increasing value goes from sheep humerus, sheep femur, cow humerus, and cow femur (Table 3). Indeed, bones of cow have an average value $(\mathrm{On} . \mathrm{Dn}=3.7)$ higher of $+37 \%$ than sheep $(\mathrm{On} . \mathrm{Dn}=2.6)$. Other interesting differences are in osteon eccentricity, as the lesser value is in sheep humerus (0.43). In contrast, the higher value is in cow femur (0.78) and intermediate values in sheep femur (0.64) and cow humerus (0.65). It means that the osteons of sheep humerus are almost circular, and 
Fig. 2 Histological features of sheep bones. $\mathbf{a}$ and $\mathbf{b}$ humerus; $\mathbf{c}$ and $\mathbf{d}$ femur. Plexiform bone tissue (a, c) and irregular Haversian tissue (b, d). Bar $=80 \mu \mathrm{m}$
Fig. 3 Histological features of cow bones. $\mathbf{a}$ and $\mathbf{c}$ humerus; $\mathbf{b}$ and $\mathbf{d}$ femur. a plexiform bone tissue; b irregular Haversian tissue; $\mathbf{c}$ and $\mathbf{d}$ dense Haversian tissue. Bar $=80 \mu \mathrm{m}$
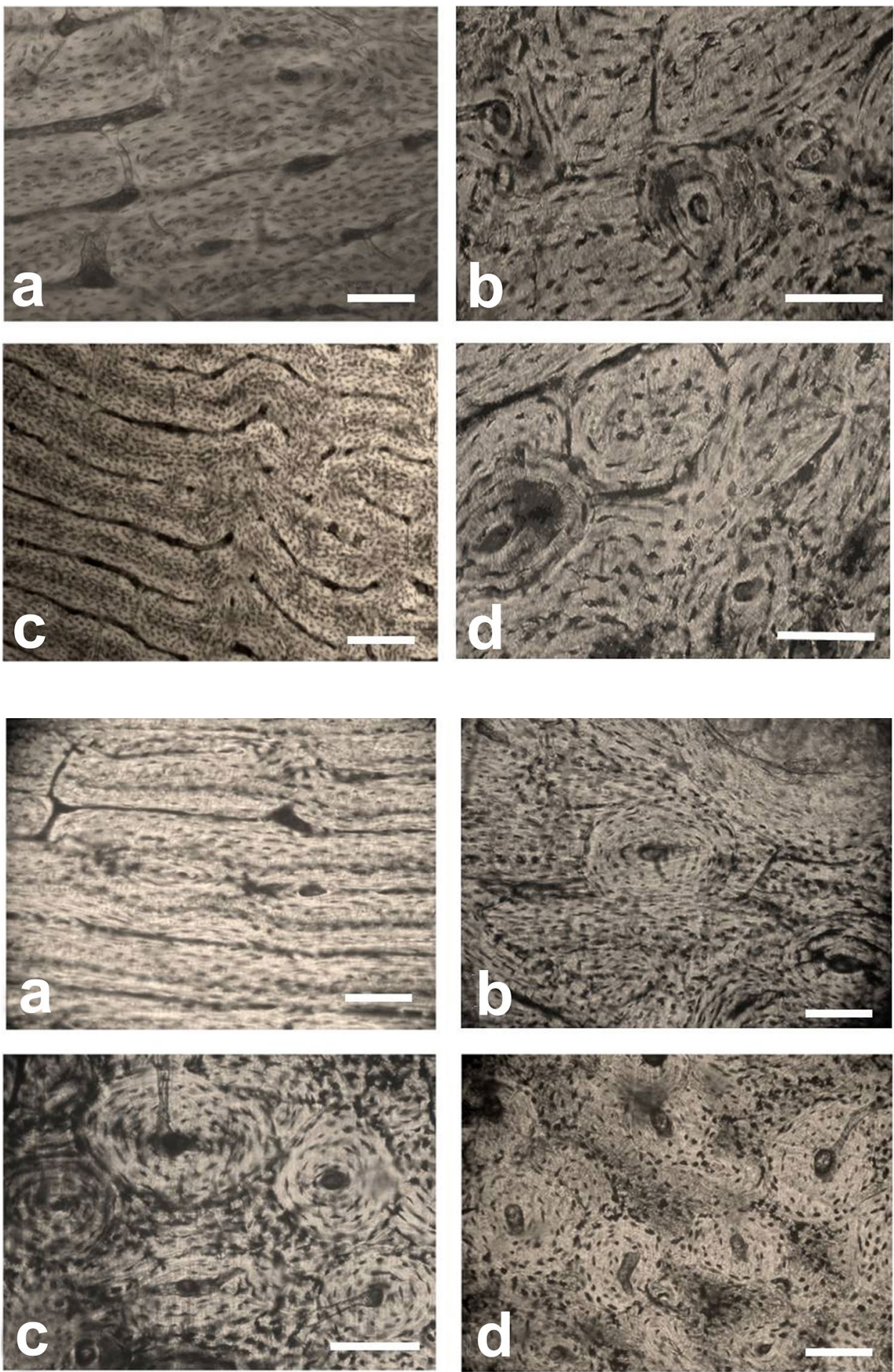

osteons of cow femur are relatively elliptical. Simultaneously, femoral osteons of both species are more elliptical than those of humerus for $+48 \%$ in sheep and $+20 \%$ in the cow.

Regarding the size of the Haversian canals, other differences can be noted among bones and species (Table 3). The increasing order of the mean diameter (HC.Dm) concerns sheep femur, sheep humerus, cow femur, and cow humerus. The Haversian canals of cow bones are always bigger than corresponding bones of sheep, but they are wider in the humerus than in femur within each species. The eccentricity of Haversian canals is more pronounced than that of corresponding osteons always except for the femur of sheep. The increasing order of eccentricity 
Fig. 4 Osteons of sheep (a humerus) and cow (b femur). It can be noted the different number of bone lamellae (4-5 in sheep and 8-9 in cow) and the size at the same magnification. $\mathrm{Bar}=60 \mu \mathrm{m}$
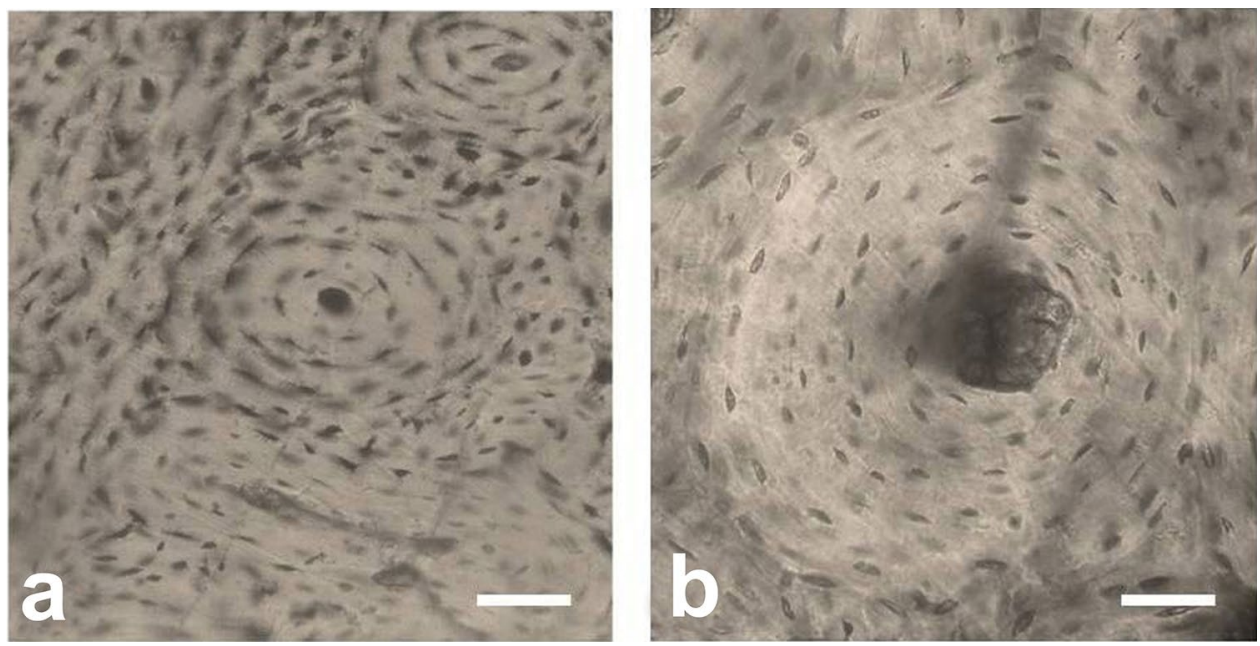

goes from sheep humerus, sheep femur, cow humerus, and cow femur.

The intraspecies comparison between the osteon diameter (On.Dm) and Haversian canal diameter (HC.Dm) in humerus and femur shows a moderate positive correlation in the humerus of sheep $(r=0.634)$, a low positive correlation in the femur of sheep $(r=0.431)$ and the humerus of the cow $(r=0.465)$, and a little positive if any correlation in the femur of the cow $(r=0.279)$. The regression lines were drawn in linear plotters (Fig. 5), and their equations are reported in Table 4 . The analysis of variance with posthoc test within and between groups for On.Dm (Table 5) highlights significant results when considering sheep humerus with sheep femur $(p<0.001)$, sheep femur with cow femur $(p<0.05)$ and cow humerus with cow femur $(p<0.05)$. The significant results for HC.Dm (Table 5) are considering sheep humerus with cow humerus $(p<0.05)$,

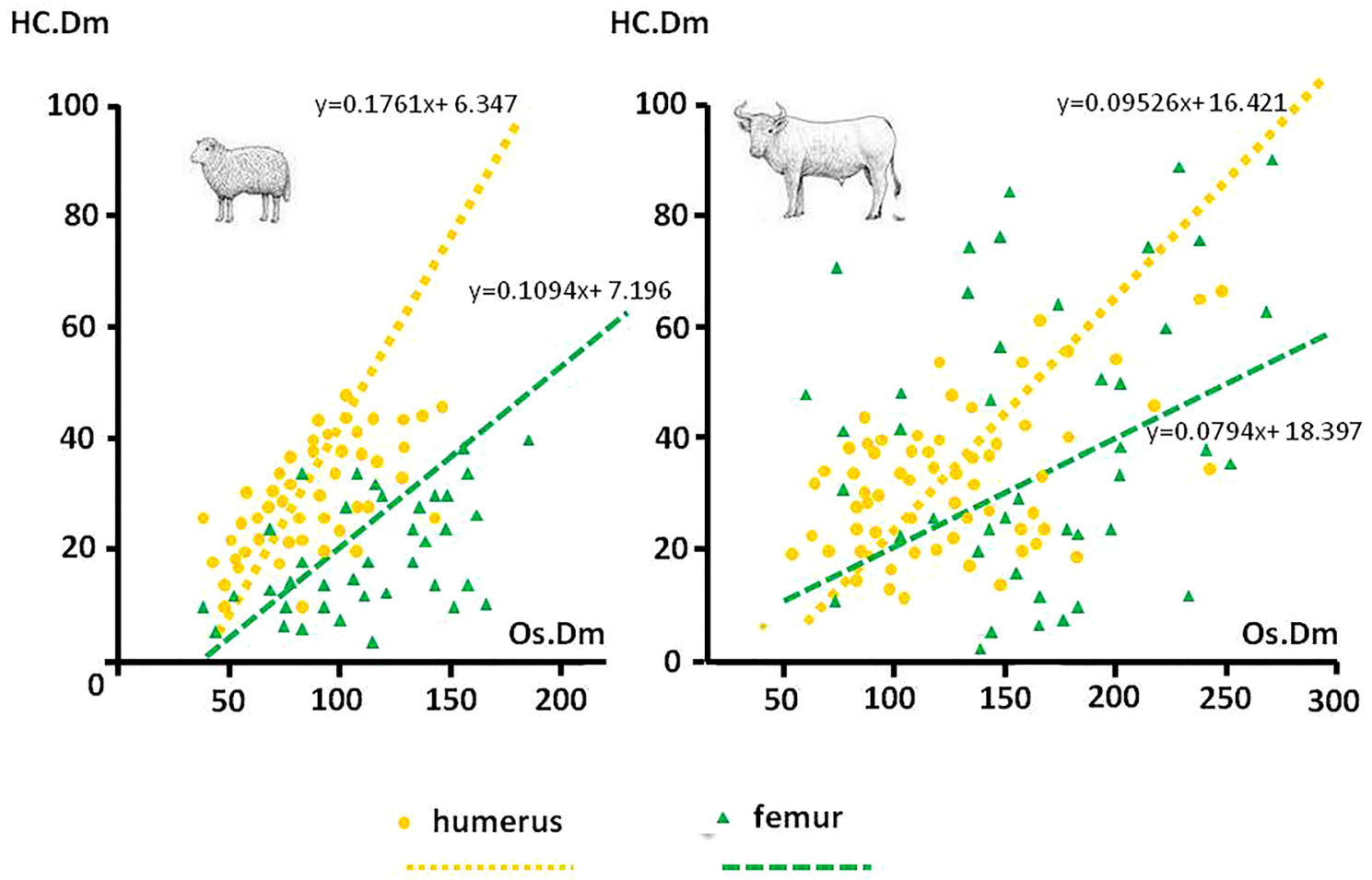

Fig. 5 Scatter plots showing the correlation between mean osteon diameter (On.Dm) and mean Haversian canal diameter (HC.Dm) both in humerus and in femur. The functions of each regression line are also reported. Left: sheep; right: cow. Values are expressed in $\mu \mathrm{m}$ 
Table 4 Statistical data on the variance of osteonal diameter (On.Dm), Pearson's correlation and regression line functions of the correlation between On.Dm and Haversian canal diameter (HC.Dm) distinct for species and bone type
Table 5 Statistical data on ANOVA one-way and analysis of significance of the variance of osteonal diameter (On.Dm) and Haversian canal diameter (HC.Dm) with Bonferroni posthoc test

\begin{tabular}{|c|c|c|c|c|}
\hline & Variance & HC.Dm & & \\
\hline & & $\begin{array}{l}\text { Pearson's coef- } \\
\text { ficient }(r)\end{array}$ & function of regression line & correlation \\
\hline On.Dm & & & & \\
\hline Sheep (Ovis & & & & \\
\hline Humerus & 392.74 & 0.634 & HC.Dm $=0.1761$ On.Dm +6.347 & $* * *$ \\
\hline Femur & 865.46 & 0.431 & HC.Dm $=0.1094$ On.Dm + 7.196 & ** \\
\hline All bones & 704.22 & 0.247 & HC.Dm $=0.0863$ On.Dm +14.638 & * \\
\hline Cow (Bosta & & & & \\
\hline Humerus & $2,438.15$ & 0.465 & HC.Dm $=0.09526$ On.Dm +16.421 & ** \\
\hline Femur & $3,084.21$ & 0.279 & HC.Dm $=0.0794$ On.Dm +18.397 & * \\
\hline All bones & $2,942.78$ & 0.049 & HC.Dm $=0.0988$ On.Dm +17.412 & * \\
\hline Sheep and cc & & & & \\
\hline Humeri & $1,306.51$ & 0.482 & HC.Dm $=0.2075$ On.Dm +16.862 & ** \\
\hline Femora & $2,139.13$ & 0.367 & HC.Dm $=0.1843$ On.Dm + 10.368 & ** \\
\hline All bones & $1,866.28$ & 0.445 & HC.Dm $=0.1382$ On.Dm + 11.455 & ** \\
\hline
\end{tabular}

Correlation: *** moderate positive; $* *$ low positive; $*$ little if any correlation

\begin{tabular}{llllll}
\hline & & Cov & $F$ & $p$ & $*$ \\
\hline Ovis aries humerus vs. Ovis aries femur & On.Dm & -286 & 14.322 & $6.47 \mathrm{E}-05$ & $*$ \\
& HC.Dm & -12.37 & 49.28 & $3.82 \mathrm{E}-10$ & $*$ \\
Ovis aries humerus vs. Bos taurus humerus & On.Dm & -9.44 & 0.6382 & 0.4658 & - \\
& HC.Dm & -7.85 & 5.584 & 0.043 & $*$ \\
Ovis aries femur vs. Bos taurus femur & On.Dm & -154.1 & 4.626 & 0.067 & $*$ \\
& HC.Dm & -7.67 & 26.781 & $3.26 \mathrm{E}-7$ & $*$ \\
Bos taurus humerus vs. Bos taurus femur & On.Dm & -278.3 & 11.435 & $1.94 \mathrm{E}-3$ & $*$ \\
& HC.Dm & 16.42 & 0.724 & 0.473 & - \\
\hline
\end{tabular}

Cov covariance; $F F$ statistical value of variance as the ratio of $F$ between and $F$ within groups; $p$ significance value with $F$ crit $=3.918 ; *$ significant value $\left(p^{<} 0.05\right)$ sheep humerus with sheep femur $(\mathrm{p}<0.001)$, and sheep femur with cow femur $(p<0.001)$.

To summarize the scaling differences between sheep and cow, the ratio cow/sheep variables (multiplicative coefficients) of macroscopical and microscopical bone features are reported in Table 6. It could be observed that from the whole body to histological levels, its value descends from $\times 10$ to just over one.

\section{Discussion}

The results achieved from different levels of comparison between sheep and cows are summarized in Table 6. The multiplicative coefficients are comprised within a range from 1.04 to 13.8 , and they are classifiable in 4 orders of magnitude (groups A, B, C, D). Their values decrease from macroscopical to microscopical levels. Moreover, the first three groups $(\mathrm{A}, \mathrm{B}, \mathrm{C})$ refer to the macroscopical features and are subjected to the allometric scaling. In contrast, the last group (D) refers to the microscopical features and seems to respect different rules. When comparing the body mass of the whole body of sheep and cow, the multiplicative index (10.7) is almost the same as that of bone weight (11.0 for combined bones). This group (group A) corresponds to the parameters involving three dimensions (3D) and their values increase to the cube (value ${ }^{3}$ ) ranging from 8.9 to 13.8 . The bone macroscopical parameters whose values increase linearly involving one dimension (1D), such as the greatest length (GL) and the diaphysis diameter (DD), belong to the second group (group B). Values of their multiplicative coefficients are comprised from 1.8 to 2.5. The bone parameters whose values increase in a quadratic way (value ${ }^{2}$ ), such as those referring to areas (D1, D2, D3) involving two dimensions (2D), show multiplicative coefficients comprised from 3.8 to 6.5 (group C). All these groups of bone parameters compared at macroscopical level (groups A, B, C) are subject to mathematical laws whereby if a length doubles, an area that depends on that 
Table 6 List of macro- and microscopical features of the bones with the corresponding multiplicative coefficients

showing the scale linking sheep and cow

\begin{tabular}{|c|c|c|c|c|}
\hline & $\begin{array}{l}\text { Multiplicative } \\
\text { coefficients }\end{array}$ & Dimension & Orders of magnitude & Comparison levels \\
\hline Body & & & & Macroscopical \\
\hline \multicolumn{5}{|l|}{$\mathrm{BM}$} \\
\hline Whole body & 10.7 & $3 \mathrm{D}$ & Group A & \\
\hline \multicolumn{5}{|l|}{ Bones } \\
\hline \multicolumn{5}{|l|}{ W } \\
\hline Humerus & 8.9 & & & \\
\hline Femur & 13.8 & & & \\
\hline Combined & 11.0 & & & \\
\hline \multicolumn{5}{|l|}{ GL } \\
\hline Humerus & 1.8 & $1 \mathrm{D}$ & Group B & \\
\hline Femur & 1.9 & & & \\
\hline Combined & 1.9 & & & \\
\hline \multicolumn{5}{|l|}{$\mathrm{DD}$} \\
\hline Humerus & 2.5 & & & \\
\hline Femur & 2.2 & & & \\
\hline Combined & 2.3 & & & \\
\hline \multicolumn{5}{|l|}{ D1 } \\
\hline Humerus & 6.4 & $2 \mathrm{D}$ & Group C & \\
\hline Femur & 4.8 & & & \\
\hline Combined & 5.6 & & & \\
\hline \multicolumn{5}{|l|}{ D2 } \\
\hline Humerus & 6.0 & & & \\
\hline Femur & 3.8 & & & \\
\hline Combined & 4.7 & & & \\
\hline \multicolumn{5}{|l|}{ D3 } \\
\hline Humerus & 6.5 & & & \\
\hline Femur & 5.6 & & & \\
\hline Combined & 6.1 & & & \\
\hline \multicolumn{5}{|l|}{ Osteons } \\
\hline On.Dm & & & & \\
\hline
\end{tabular}


Table 6 (continued)

\begin{tabular}{|c|c|c|c|c|}
\hline & $\begin{array}{l}\text { Multiplicative } \\
\text { coefficients }\end{array}$ & Dimension & Orders of magnitude & Comparison levels \\
\hline Humerus & 1.04 & $1 \mathrm{D}$ & Group D & Microscopical \\
\hline Femur & 1.06 & & & \\
\hline Combined & 1.05 & & & \\
\hline \multicolumn{5}{|l|}{ On.Pm } \\
\hline Humerus & 1.05 & & & \\
\hline Femur & 1.07 & & & \\
\hline Combined & 1.06 & & & \\
\hline \multicolumn{5}{|l|}{ On.Ar } \\
\hline Humerus & 1.08 & $2 \mathrm{D}$ & & \\
\hline Femur & 1.05 & & & \\
\hline Combined & 1.07 & & & \\
\hline \multicolumn{5}{|c|}{ Haversian canals } \\
\hline \multicolumn{5}{|l|}{ HC.Dm } \\
\hline Humerus & 1.27 & $1 \mathrm{D}$ & & \\
\hline Femur & 1.26 & & & \\
\hline Combined & 1.27 & & & \\
\hline \multicolumn{5}{|l|}{ HC.Pm } \\
\hline Humerus & 1.45 & & & \\
\hline Femur & 1.48 & & & \\
\hline Combined & 1.46 & & & \\
\hline \multicolumn{5}{|l|}{ HC.Ar } \\
\hline Humerus & 1.86 & $2 \mathrm{D}$ & & \\
\hline Femur & 1.71 & & & \\
\hline Combined & 1.77 & & & \\
\hline
\end{tabular}

The multiplicative coefficients are ratio cow/sheep

length increases by 4 times and a volume that depends on which length increases by 8 times. In other words, $\times 2, \times 4$ and $\times 8$ could be the multiplicative coefficients respectively of liner length (1D), area (2D) and volume (3D) in the case in which a length doubles. In our case, when comparing the sizes of bones (GL and DD) of sheep and cow, their value increases of a mean of 2.1 times (mean value of GL and DD of combined bones). The area values (D1, D2, D3) increase a little more 4 times and, finally, the bone weight (W) and the body-mass (BM) increase a mean of about 10.8 times. This shows that, at the macroscopical level, bones are subjected to these geometrical laws in a fairly reliable way.

As regards the microscopical level of comparison, surprisingly, all parameters considered (group D) differ from the other groups. Neither linear sizes as diameters and perimeter (On.Dm, On.Pm, HC.Dm, HC.Pm) nor area sizes (On.Ar, HC.Ar) do not respond to the multiplicative coefficient for linear length and areas respectively. Indeed, despite the cow weighing more than 10 times the sheep, the measurements of the microscopic structure, osteons and Haversian canals, are very similar (values of multiplicative coefficients comprised from 1.04 to 1.86 ). This statement is particularly true for osteons, whose multiplicative coefficients of all parameters (On.Dm, On.Pm, On.Ar) have a mean value of 1.06. In Haversian canals, the mean value of all parameters (HC.Dm, HC.Pm, HC.Ar) is 1.51. In the specific case of HC.Ar the multiplicative parameter is near two-fold different between the species. All the bone microstructures seem to have negative allometry being poor dependent on body mass.

An explanation for this discrepancy between the macroscopic and microscopic levels of comparison could be advanced, considering that the macroscopic parameters are unique. In contrast, the microscopic structures (i.e., osteons with Haversian canals) are numerous. Although their 
measurements are very similar, their number could vary when comparing sheep and cows. Indeed, it could be noted that the osteon population density (On.Dn) is higher $(+37 \%)$ in the cow (mean value 3.7) than sheep (mean value 2.7). Based on this datum, it can be said that the greater resistance to mechanical stress imposed on the bones by the large weight of the bovine is supported by a greater number of osteons in this species. Another morphological feature that suggests a greater capability of the bovine osteons to resist mechanical stress is their higher eccentricity than sheep. In other species, a higher value of eccentricity has been described in those animals with remarkable locomotor skills, such as horse, goat, moufflon, wild boar, rabbit (Locke 2004; Zedda et al. 2008, 2017, 2019, 2020) and man (Goldman et al. 2005; Pfeiffer et al. 2006). Negative allometry in osteon size has also been described by Felder et al. (2017) taking into consideration humeri and femora of 56 mammal species and by Barak et al. (2013) in trabecular bone of mice, rats and man. Our results are also consistent with Jowsey (1966) who says that osteon size increases with body size only for species less than $10 \mathrm{~kg}$.

The few histomorphometric differences between humerus and femur in each species could be explained considering that the femur is more involved in mechanical stresses than the humerus. It may be due to the different functions that the limbs have in locomotion. It is well known that in mammals, quadrupeds thoracic and pelvic limbs are differently specialized for locomotion: thoracic limbs carry more than half of static body weight. They are designed to absorb ground impact as the body is thrown forward by the pelvic limbs. Thoracic limbs improve gait efficiency by converting the kinetic energy of downward movement into the potential energy of stretched muscles and ligaments, which rebound to generate upward movement. Pelvic limbs are the engine of locomotion, designed to propel the trunk forward (McNeill Alexander 2003). The musculature that we find around the femur (thigh muscles) is, in fact, more developed and numerous than that around the humerus (arm muscles). Artiodactyla are also usually considered as a biomechanically homogeneous group (Christiansen 1999).

Among the studies performed to detect scaling relationships between long bone dimensions and body mass, a pivotal role of growth plates during limb development has been highlighted to understand the evolutionary diversity of limb proportions in mammals (Cooper 2019; Rolian 2020). A highly conservative relationship between the circumference of stylopodial bones and body mass has been demonstrated in a comprehensive dataset of quadrupedal terrestrial vertebrates (Campione and Evans 2012). Moreover, weight gain can increase bone mass and alter bone microstructure by inducing an adaptive response to increased mechanical loading (Iwaniec and Turner 2016). Cooper et al. (2007) found that lighter people have a much larger Haversian canal diameter than heavier individuals. It implies that heavier people have thicker osteon walls, resulting in proportionally more durable and more resistant bones, which in turn may respond to higher loads (Britz et al. 2009). The results of Mishra and Knothe Tate (2003) indicate that large osteons in rats provide higher energy efficiency, which makes them stronger. That gives them better survival compared to heavier mammals having a smaller osteon size. The biological significance of the formation of smaller osteons lies in response to a specific lifestyle (for example, jumping, all four limb movements), which determined that the weightbearing bones require increased resistance to micro and macro fractures (van Oers et al. 2008). Many studies have been performed increasing the species number and elaborating mathematical formulas to estimate the body mass of a mammal starting from the osteon diameter (Mishra and Knothe Tate 2003; Pfeiffer et al. 2006; Brits et al. 2014; Felder et al. 2017). The common thread of all these studies is that all mammal species considered are characterized not only by different body mass but also by different locomotory style. The stylopodial bones (humerus and femur) are subjected to very different mechanical stress, even depending on body mass loads. The exact distinction of which factors affect osteon size is a wide problem because all parameters are often strictly connected. For example, the increase in the body mass of animals is almost always associated with a reduction in mechanical stress due to a decrease in fast movements and gaits (Biewener 2005).

The animals chosen in our work, sheep and cow, are different in body mass (about 10 times) but with the same locomotor activity. Both species are grazing ruminant herbivores that walking slowly for most of the day. They prefer flat grassy plains and avoid rough terrains.

\section{Conclusion}

In conclusion, while the macroscopic level of comparison shows scaling differences between stylopodial bones of sheep and cow subjected to mathematical laws. The histomorphometrical analyses do not highlight differences in osteon and Haversian canals dimensions. Therefore, it could be postulated that the body mass does not affect the size of the bone microstructure, probably more sensitive to other factors such as lifestyle and locomotor ability.

Funding Open Access funding provided by Università degli Studi di Sassari.

\section{Compliance with ethical standards}

Conflicts of interest The authors declare that they have no conflict of interest. 
Ethical approval This article does not contain any studies with animals performed by any of the authors. The authors declare that the animal bones used in this work did not come from live animals and, therefore, the research protocol has not passed through the examination of the Department Ethics Committee.

Open Access This article is licensed under a Creative Commons Attribution 4.0 International License, which permits use, sharing, adaptation, distribution and reproduction in any medium or format, as long as you give appropriate credit to the original author(s) and the source, provide a link to the Creative Commons licence, and indicate if changes were made. The images or other third party material in this article are included in the article's Creative Commons licence, unless indicated otherwise in a credit line to the material. If material is not included in the article's Creative Commons licence and your intended use is not permitted by statutory regulation or exceeds the permitted use, you will need to obtain permission directly from the copyright holder. To view a copy of this licence, visit http://creativecommons.org/licenses/by/4.0/.

\section{References}

Alioniene I (2004) Estimation of the microstructure of suids long bone. In: Fabis M, Kramarova M (eds) Abstract of the international conference of the Animal Palaeopathology Working Group of the ICAZ. Slovak Agricultural University, Nitra, p 5

Ascenzi MG, Roe AK (2012) The osteon: the micromechanical unit of compact bone. Front Biosci 17:1551-1581. https://doi. org/10.2741/4003

Barak MM, Lieberman DE, Hublin J-J (2013) Of mice, rats and man: trabecular bone architecture in mammals scales to body mass with negative allometry. J Struct Biol 183:123-131

Barone R (1980) Anatomie comparée des mammifères domestiques. Osteologie, vol 1. Vigot Frères, Paris

Bell KL, Loveridge N, Reeve J, Thomas CDL, Feik SA, Clement JG (2001) Super-osteon (remodeling clusters) in the cortex of the femoral shaft: influence of age and gender. Anat Rec 264:378386. https://doi.org/10.1002/ar.10014

Biewener AA (2005) Biomechanical consequences of scaling. J Exp Biol 208:1665-1676. https://doi.org/10.1242/jeb.01520

Brits D, Steyn M, L'Abbe EN (2014) A histomorphological analysis of human and non-human femora. Int J Legal Med 128:369-377. https://doi.org/10.1007/s00414-013-0854-3

Britz HM, Thomas CDL, Clement JG, Cooper DML (2009) The relation of femoral osteon geometry to age, sex, height and weight. Bone 45:77-83. https://doi.org/10.1016/j.bone.2009.03.654

Burr DB (2002) Targeted and non-targeted remodeling. Bone 30:2-4. https://doi.org/10.1016/s8756-3282(01)00619-6

Caeiro JR, Gonzalez P, Guede D (2013) Biomechanics and bone ( \& II): Trials in different hierarchical levels of bone and alternative tools for the determination of bone strength. Rev Osteoporos Metab Miner 5:99-108. https://doi.org/10.4321/S1889-836X201300 0200007

Campione NE, Evans DC (2012) A universal scaling relationship between body mass and proximal limb bone dimensions in quadrupedal terrestrial tetrapods. BMC Biol 10:1-21. https://doi. org/10.1186/1741-7007-10-60

Christiansen P (1999) Scaling of the limb long bones to body mass in terrestrial mammals. J Morphol 239:167-190

Cooper KL (2019) Developmental and evolutionary allometry of the mammalian limb skeleton. Integr Comp Biol 59:1356-1368. https ://doi.org/10.1093/icb/icz082
Cooper DML, Thomas CDL, Clement JG, Turinsky AL, Sensen CW, Hallgrimsson B (2007) Age-dependent change in the 3D structure of cortical porosity at the human femoral midshaft. Bone 40:957-965. https://doi.org/10.1016/j.bone.2006.11.011

Dittman K (2003) Histomorphometrische untersuchung der knochenmikrostructur von primate and haustieren mit dem ziel der speziesdentifikaton unter berücksichtingung von domestikationseffekten. Anthropol Anz 61:175-188. https://doi.org/10.1127/ anthranz/61/2003/175

Felder AA, Phillips C, Cornish H, Cooke M, Hutchinson JR, Doube M (2017) Secondary osteons scale allometrically in mammalian humerus and femur. R Soc Open Sci 4:170431. https://doi. org/10.1098/rsos.170431

Francillon-Vieillot H, de Buffrénil V, Castanet J, Geraudie J, Meunier FJ, Sire JY, Zylberberg L, de Ricqles A (1989) Microstructure and mineralization of skeletal vertebral tissues. In: Carter JG (ed) Skeletal biomineralization: patterns, processes and evolutionary trands. Springer, Berlin, pp 471-530

Galileo G (1638) Discorsi e dimostrazioni matematiche intorno a due nuove scienze attinenti la meccanica e i movimenti locali. Elzeviri, Leida

Gentry AW (1970) The Bovidae (Mammalia) of the Fort Ternan fossil fauna. In: Leakey LSB, Savage RJG (eds) Fossil vertebrates of Africa. Academic Press, London, pp 243-323

Gibson VA, Stover SM, Gibeling JC, Hazelwood SJ, Martin RB (2006) Osteonal effects on elastic modulus and fatigue life in equine bone. J Biomech 39:217-225. https://doi.org/10.1016/j. jbiomech.2004.12.002

Giua S, Farina V, Cacchioli A, Ravanetti F, Carcupino M, Mohadero Novas M, Zedda M (2014) Comparative histology of the femur between mouflon (Ovis aries musimon) and sheep (Ovis aries aries). J Biol Res 87:74-77. https://doi.org/10.4081/ jbr.2014.4743

Goldman HM, Thomas CDL, Clement JG, Bromage TG (2005) Relationships among microstructural properties of bone at the human midshaft femur. J Anat 206:127-139. https://doi.org/10.111 1/j.1469-7580.2005.00385.x

Goldman HM, Hampson NA, Guth JJ, Lin D, Jepsen KJ (2014) Intracortical remodeling parameters are associated with measures of bone robustness: intracortical remodeling and bone robustness. Anat Rec 297:1817-1828. https://doi.org/10.1002/ar.22962

Hillier ML, Bell LS (2007) Differentiating human bone from animal bone: a review of histological methods. J Forensic Sci 52:249263. https://doi.org/10.1111/j.1556-4029.2006.00368.x

Hinkle DE, Wiersma W, Jurs SG (2003) Rule of thumb for interpreting the size of a correlation coefficient. In: Applied Statistic for the Behavioral Sciences, 5th Ed, Boston, pp 108-110

Iwaniec UT, Turner RT (2016) Influence of body weight on bone mass, architecture and turnover. J Endocrinol 230:R115-R130. https:// doi.org/10.1530/JOE-16-0089

Joshi VK (2006) What makes rats perky and dinosaurus tardy? Boloji Publishing https://www.boloji.com/articles/2776. Accessed 30 Apr 2006

Jowsey J (1966) Studies of haversian systems in man and some animals. J Anat 100:857-864

Locke M (2004) Structure of long bones in mammals. J Morphol 262:546-565. https://doi.org/10.1002/jmor. 10282

Lozupone E, Favia A (1990) The structure of the trabeculae of cancellous bone. 2. Long bones and mastoid. Calcif Tissue Int 46:367372. https://doi.org/10.1007/BF02554966

Mainland I, Schutkowski H, Thomson AF (2007) Macro- and micromorphological features of lifestyle differences in pigs and wild boar. Antrophozoologica 42:89-106

Martin RB (2003) Fatigue damage, remodeling, and the minimization of skeletal weight. J Theor Biol 220:271-276. https://doi. org/10.1006/jtbi.2003.3148 
Martin RB, Pickett JC, Zinaich S (1980) Studies of skeletal remodeling in aging men. Clin Orthop Relat Res 149:268-282

Matolcsi J (1970) Historische Erforschung der Körpergröße des Rindes auf Grund von ungarischem Knochenmaterial. Zeitschrift für Tierzüchtung und Züchtungsbiologie 87:89-137. https://doi. org/10.1111/j.1439-0388.1970.tb01330.x

May E, Teichert UM (2001) Berechnung der Widerristhöhe bei Schafen aus Extremitätenmaßen mit Hilfe von Regressionsgleichungen oder Faktoren? In: Buitenhuis H, Prummel W (eds) Animals and man in the past. ARC-Publicatie, Groningen, pp 33-37

McNeill Alexander R (2003) Principles of animal locomotion. Princeton University Press, Princeton, p 384

Mishra S, Knothe Tate ML (2003) Effect of lacunocanalicular architecture on hydraulic conductance in bone tissue: implications for bone health and evolution. Anat Rec A Discov Mol Cell Evol Biol 273:262-752. https://doi.org/10.1002/ar.a.10079

Mysterud A, Perez-Barberia FJ, Gordon IJ (2001) The effect of season, sex and feeding style on home range area versus body mass scaling in temperate ruminants. Oecologia 127:30-39. https://doi. org/10.1007/s004420000562

Nacarino-Meneses C, Jordana X, Kohler M (2016) First approach to bone histology and skeletochronology of Equus hemionus. CR Palevol 15:267-277. https://doi.org/10.1016/j.crpv.2015.02.005

Nguyen TV, Livshits G, Center JR, Yakovenko K, Eisman JA (2003) Genetic determination of bone mineral density: evidence for a major gene. J Clin Endocrinol Metab 88:3614-3620. https://doi. org/10.1210/jc.2002-030026

Owerkowicz T, Crompton AW (1995) Bone of contention in the evolution of endothermy. J Verteb Paleontol 15:47A

Parfitt AM, Drezner MK, Glorieux FH, Kanis JA, Malluche H, Meunier P, Ott SM, Recker RR (1987) Bone histomorphometry: standardization of nomenclature, symbols, and units: report of the asbmr histomorphometry nomenclature committee. J Bone Miner Res 2:595-610. https://doi.org/10.1002/jbmr.5650020617

Pfeiffer S, Crowder C, Harrington L, Brown M (2006) Secondary osteon and Haversian canal dimensions as behavioral indicators. Am J Phys Anthropol 131:460-468. https://doi.org/10.1002/ ajpa.20454

Rolian C (2020) Endochondral ossification and the evolution of limb proportions. Wiley Interdiscip Rev Dev Biol 9:e373. https://doi. org/10.1002/wdev.373

Ruffing JA, Cosman F, Zion M, Tendy S, Garrett P, Lindsay R, Nieves JW (2006) Determinants of bone mass and bone size in a large cohort of physically active young adult men. Nutr Metab 3:14. https://doi.org/10.1186/1743-7075-3-14

Schmidt-Nielsen K (1984) Scaling: why is body size so important? Cambridge University Press, Cambridge, p 241

Scott KM (1990) Postcranial dimensions of ungulates as predictors of body mass. In: Damuth J, MacFadden J (eds) Body size in Mammalian palaeobiology: estimation and biological implications. Cambridge University Press, Cambridge, pp 301-337

Skedros JG, Sybrowsky CL, Parry TR, Bloebaum RD (2003) Regional differences in cortical bone organization and microdamage prevalence in Rocky Mountain mule deer. Anat Rec A Discov Mol Cell Evol Biol 274:837-850. https://doi.org/10.1002/ar.a.10102

Skedros JG, Knight AN, Clark GC, Crowder CM, Dominguez VM, Qiu S, Mulhern DM, Donahue SW, Busse B, Hulsey BI, Zedda M, Sorenson SM (2013) Scaling of Haversian canal surface area to secondary osteon bone volume in ribs and limb bones. Am J Phys Anthropol 151:230-244. https://doi.org/10.1002/ajpa.22270

Stock JT, Shaw CN (2007) Which measures of diaphyseal robusticity are robust? A comparison of external methods of quantifying the strength of long bone diaphyses to cross-sectional geometric properties. Am J Phys Anthropol 134:412-423. https://doi. org/10.1002/ajpa.20686

Teichert M (1975) Osteologische Untersuchungen zur Berechnung der Widerristhöhe bei Schafen. In: Clason AT (ed) Archaeozoological studies. North Holland and American Elsevier, Amsterdam, pp 51-69

Urbanova P, Novotny V (2005) Distinguishing between human and non-human bones: histometric method for forensic anthropology. Anthropologie 43:77-85

van Oers RFM, Ruimerman R, van Rietbergen B, Hilbers PAJ, Huiskes R (2008) Relating osteon diameter to strain. Bone 43:476-482. https://doi.org/10.1016/j.bone.2008.05.015

Zedda M, Lepore G, Manca P, Chisu V, Farina V (2008) Comparative bone histology of adult horses (Equus caballus) and cows (Bos taurus). Anat Histol Embryol 37:442-445. https://doi.org/10.111 1/j.1439-0264.2008.00878.x

Zedda M, Lepore G, Biggio GP, Gadau S, Mura E, Farina V (2015) Morphology, morphometry and spatial distribution of secondary osteons in equine femur. Anat Histol Embryol 44:328-332. https ://doi.org/10.1111/ahe.12141

Zedda M, Palombo MR, Brits D, Carcupino M, Sathe V, Cacchioli A, Farina V (2017) Differences in femoral morphology between sheep (Ovis aries) and goat (Capra hircus): macroscopic and microscopic observations. Zoomorphology 136:145-158. https ://doi.org/10.1007/s00435-016-0329-4

Zedda M, Brits D, Giua S, Farina V (2019) Distinguishing domestic pig femora and tibiae from wild boar through microscopic analyses. Zoomorphology 138:159-170. https://doi.org/10.1007/s0043 5-018-0426-7

Zedda M, Sathe V, Chakraborty P, Palombo MR, Farina V (2020) A first comparison of bone histomorphometry in extant domestic horses (Equus caballus Linnaeus, 1758) and a Pleistocene Indian wild horse (Equus namadicus Falconer \& Cautley, 1849). Integr Zool 15:448-460. https://doi.org/10.1111/1749-4877.12444

Publisher's Note Springer Nature remains neutral with regard to jurisdictional claims in published maps and institutional affiliations. 